\title{
CONDITIONED RESPONSES OF HIPPOCAMPAL AND OTHER NEURONS $^{1}$
}

\author{
J. OldS AND T. Hirano \\ Brain Research Laboratory, Department of Psychology, The University of Michigan, Ann. Arbor, Mich. 48104 (U.S.A.)
}

(Accepted for publication: June 10, 1968)

\section{INTRODUCTION}

Previous studies of neuron changes during conditioning have involved either surgical and paralytic restraints (Yoshii and Ogura 1960; Kamikawa et al. 1964) or free behavior in chronic animals (Buchwald et al. 1966; Travis and Sparks 1967; Ellison et al., in press). The search for neural traces of critical changes in learning has thus been clouded by the surgical and paralytic procedures or confounded by the correlates of the new conditioned responses. There has also been confusion resulting from the sensitizing effects of the unconditioned stimulus (US) and from changes in attention level which occur as the conditioned stimulus (CS) becomes a sign of a more or less significant unconditioned stimulus. New techniques have permitted us to study conditioned neuron responses that were not correlated with new skeletal movements or with changing states of sensitization or arousal in animals that were neither anesthetized nor paralyzed.

Our object was to obtain evidence which might implicate structures of the hypothalamohippocampal system in temporary information storage and in anticipatory or other internal responses divorced from immediate skeletal and arousal patterns. Interest in the hippocampus and its related subcortical structures stemmed from several kinds of experiments which related it in one way or another to temporary information storage. There were first the observations indicating a failure of some informationholding functions in humans after hippocampal

1 These studies were supported by research grants from the U.S. Public Health Service. damage (Milner 1958). Second, there were diffculties (such as poor extinction, insufficient response variability, and excessive responding to the wrong stimulus) exhibited by animals with hippocampal lesions (Orbach et al. 1960; Isaacson and Wickelgren 1962; Niki 1967). Third, there were observations of hippocampal "theta" rhythms during certain phases of learning but not in the early period when the CS was entirely novel (Pickenhain and Klingberg 1967) and not in the later period if at that time the response to the stimulus was fully determined. Finally, there were stimulation studies implicating hippocampus and its related structures in the control of drives (MacLean et al. 1962), consummatory responses (Kawakami et al. 1967), and positive and negative reinforcements (Ursin et al. 1966) which play a major role in marking information for storage or erasure. It seemed that if temporary information storage did occur in hippocampus, then hippocampal neurons might display temporary responses in the course of conditioning; and if anticipatory responses did occur in drive or reward "centers" then these might be observed during the period between the application of the conditioned stimulus and the application of the unconditioned stimulus.

\section{METHODS}

The subjects were fifteen rats. Each was prepared with 6-8 indwelling micro-electrodes and a reference lead as described by Olds et al. (1969).

Recordings were made simultaneously from 4 probes during $2 \mathrm{sec}$ intervals which included a 1 sec pre-stimulus interval and a 1 sec interval of auditory stimulation.

The CS was a $600 \mathrm{c} / \mathrm{sec}$ tone applied for a full 
second. The US was a $45 \mathrm{mg}$ food pellet supplied by a noisy food magazine with which the animal was familiar.

During a 500 trial, 3 days pre-conditioning experiment, habituation and pseudo-conditioning procedures were simultaneously employed. That is, the tone was presented repeatedly on a random basis with an average inter-trial interval of $4 \mathrm{~min}$; recordings were made prior to and during the stimulus and movement during a CS application caused its termination. The US was presented repeatedly on a different random schedule with the same average inter-trial interval; there was no correlation between the CS and the US.

During the following 300 trial, 2 days conditioning experiment, the conditions were the same in all respects except that the US was presented not on a schedule of its own but after the completion of each $1 \mathrm{sec}$ CS application. During this period, movement during the CS period or the 1 sec pre-CS period caused a cancellation of the US.

During the pre-conditioning and the conditioning experiments, the animals received all their food from the magazine. During conditioning, the animal had to learn to stand still in order to be fed. The conditioning experiment was continuous with the pre-conditioning experiment that preceded it; that is, there was no pause in the random 4 min schedule at the time of changing from the pre-conditioning to the conditioning program.

Neuronal activity was discriminated and counted automatically by a solid state device which has been described previosuly (Olds 1965, 1967; see also Olds et al. 1969).

The data presented are for the last 50 trials of the 500 trial pre-conditioning experiment, and for the last 50 trials of the 300 trial conditioning experiment; a comparison of these data taken before conditioning and after conditioning permitted detection of the changes caused by the conditioning procedure.

The data are presented in terms of the changes in spike firing rate caused by the auditory stimulus; these were quantified in terms of an early "response" (during the first $300 \mathrm{msec}$ of stimulation) and a late "response" (during the last 500 msec of stimulation). In both cases the firing rates during early or late intervals were divided by firing rates during the last $500 \mathrm{msec}$ period before stimulation and thus converted to a percentage of the corresponding base rate.

After the experiments, brains were sectioned and stained so that recording points could be localized.

\section{RESULTS}

\section{Evoked responses}

There were changes in spike firing frequencies in response to the auditory stimulus before conditioning (see Table I). One-third of the units showed $20 \%$ increments in rate during the first 300 msec. This response was short lasting; during the last half of the stimulus only $3 \%$ of the neurons (out of a total of 71) showed such increments. There were decrements during both the early and late periods in hippocampus and preoptic area.

The largest responses before conditioning were in dorsal reticular formation, where $43 \%$ of the neurons exhibited rate increments amounting to $40 \%$ during the first $300 \mathrm{msec}$. In the ventral reticular formation, hypothalamus, preoptic area and hippocampus the proportion of cases with such increments was much lower (from 5 to $10 \%$.

\section{Conditioned responses}

Conditioning caused many neurons which in pre-conditioning tests showed small increments (less than $20 \%$ ) or decrements during the first $300 \mathrm{msec}$ to exhibit increments above $20 \%$ or even above $40 \%$ after conditioning. This was particularly marked in the hippocampal and thalamic groups where conditioning caused at least a 5-fold increase in the number of units with firing rates augmented by $40 \%$ or more. It doubled the number of such large increments in hypothalamus and preoptic area and reduced the number in reticular formation where these large increments were most numerous in the first place (see Table I).

Conditioning also caused a large increase in the number of neurons whose rates were 20 or $40 \%$ above base rate during the last $500 \mathrm{msec}$ of auditory stimulation (see Fig. 1). This was apparent in all groups except in those from the ventral reticular formation. The number of cases with " 20 or $40 \%$ " responses during the late period increased 10-fold: before conditioning there were 
TABLE I

The number of units showing increments and decrements of different sizes caused by auditory stimulation before and after conditioning

\begin{tabular}{|c|c|c|c|c|c|c|c|c|c|c|}
\hline \multirow{2}{*}{ Brain area } & \multirow{2}{*}{$\begin{array}{c}N \\
\text { (units) }\end{array}$} & \multicolumn{2}{|c|}{$\begin{array}{l}\text { Rate increments } \\
\text { of } 40 \% \text { or more }\end{array}$} & \multicolumn{2}{|c|}{$\begin{array}{l}\text { Rate increments } \\
\text { of } 20 \% \text { to } 40 \%\end{array}$} & \multicolumn{2}{|c|}{$\begin{array}{l}\text { Rate changes of } \\
-5 \% \text { to }+20 \%\end{array}$} & \multicolumn{2}{|c|}{$\begin{array}{l}\text { Rate decrements } \\
\text { of } 6 \% \text { or more }\end{array}$} & \multirow{2}{*}{$\begin{array}{l}\text { Number } \\
\text { of rats }\end{array}$} \\
\hline & & $\begin{array}{l}\text { Before } \\
\text { cond. }\end{array}$ & $\begin{array}{l}\text { After } \\
\text { cond. }\end{array}$ & $\begin{array}{l}\text { Before } \\
\text { cond. }\end{array}$ & $\begin{array}{l}\text { After } \\
\text { cond. }\end{array}$ & $\begin{array}{l}\text { Before } \\
\text { cond. }\end{array}$ & $\begin{array}{l}\text { After } \\
\text { cond. }\end{array}$ & $\begin{array}{l}\text { Before } \\
\text { cond. }\end{array}$ & $\begin{array}{l}\text { After } \\
\text { cond. }\end{array}$ & \\
\hline
\end{tabular}

First 300 milliseconds

Dorsal reticular

Ventral reticular

Thalamus

Hypothalamus

Preoptic

Hippocampus

Total

Percentage

Last 500 milliseconds

\section{Dorsal reticular}

Ventral reticular

Thalamus

Hypothalamus

Preoptic

Hippocampus

Total

Percentage

7
10
8
10
17
19
71
100

3
1
0
1
1
1
7
9.9

$\begin{array}{cc}2 & 2 \\ 1 & 3 \\ 3 & 4 \\ 2 & 2 \\ 2 & 1 \\ 5 & 4 \\ 15 & 16 \\ 21.5 & 22.5\end{array}$

$\begin{array}{cc}1 & 2 \\ 6 & 6 \\ 4 & 4 \\ 2 & 6 \\ 2 & 11 \\ 2 & 10 \\ 17 & 39 \\ 23.9 & 54.9\end{array}$

$\begin{array}{cc}4 & 0 \\ 3 & 0 \\ 1 & 0 \\ 5 & 1 \\ 10 & 4 \\ 9 & 4 \\ 32 & 9 \\ 45.1 & 12.7\end{array}$

$\begin{array}{lr}0 & 5 \\ 0 & 8 \\ 0 & 6 \\ 1 & 6 \\ 3 & 13 \\ 3 & 8 \\ 7 & 15 \\ 9.9 & \end{array}$

\section{5}

8 6

$\begin{array}{rrrrrrrrrr}7 & 0 & 1 & 0 & 2 & 7 & 4 & 0 & 0 & 5 \\ 10 & 0 & 0 & 0 & 0 & 9 & 1 & 10 & 0 & 8 \\ 8 & 0 & 1 & 0 & 4 & 8 & 3 & 0 & 0 \\ 10 & 0 & 1 & 1 & 3 & 7 & 5 & 2 & 6 \\ 17 & 0 & 1 & 1 & 2 & 13 & 9 & 3 & 1 & 5 \\ 19 & 0 & 2 & 0 & 4 & 9 & 9 & 10 & 4 \\ 71 & 0 & 6 & 2 & 15 & 53 & 40 & 16 & 8 \\ 100 & 0 & 8.5 & 2.8 & 21.1 & 74.6 & 56.3 & 22.5 & 10 & 14.1\end{array}$

2 such units among the 71 tested, after conditioning there were 21 . The relative incidence of units yielding firing rates of $20 \%$ or more above baseline during the last $500 \mathrm{msec}$ was increased by conditioning from 0 to $62 \%$ in the thalamic group, 0 to $43 \%$ in the dorsal reticular group, 10 to $40 \%$ in hypothalamus, 0 to $30 \%$ in hippocampus, and from 6 to $18 \%$ in preoptic area (see Table I).

Even though hippocampus was not at the top of the list of areas yielding large responses after conditioning, the largest changes in response caused by conditioning appeared in hippocampus. This is because there were many decremental responses in hippocampus prior to conditioning, and many of these were changed to incremental responses by conditioning. The changes were quantified by subtracting each score after conditioning from the corresponding score after pseudoconditioning control tests (see Table II). There were average increments in the early response in all areas except the dorsal reticular formation where an average decrement of $30 \%$ appeared (see Fig. 2). The largest early-response

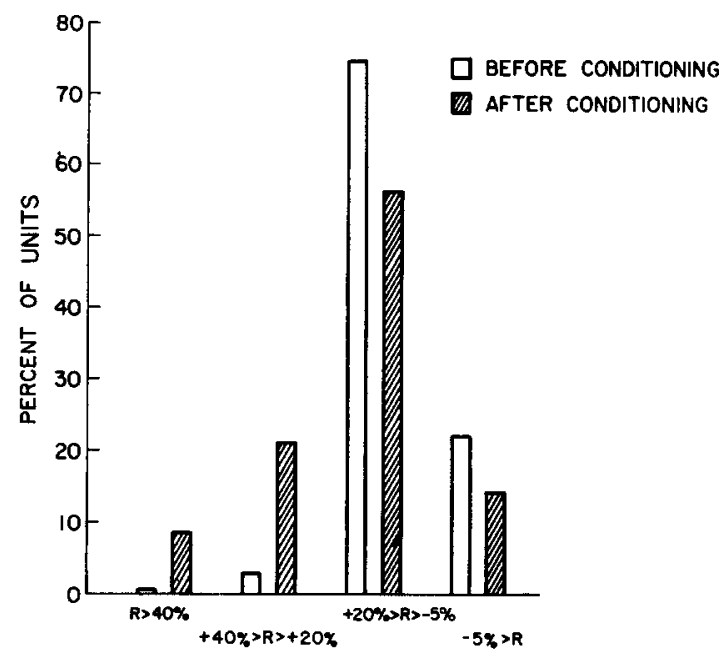

Fig. 1

Changes in firing rates in last $500 \mathrm{msec}$ of stimulation. Incidence of units with supra-normal firing rates of different percentages above baseline before and after conditioning. Symbols are as follows: $\mathrm{R}>40 \%=$ unit firing rates exceeded control rates by $40 \%$ or more; $+40 \%>R$ $>+20 \%=$ rates were $20-40 \%$ above controls; $+20 \%$ $>\mathrm{R}>-5 \%=$ rates ranged from $5 \%$ below to $20 \%$ above controls; $-5 \%>\mathrm{R}=$ rates were $5 \%$ or more below control rates.

Electroenceph. clin. Neurophysiol., 1969, 26: 159-166 
TABLE II

The mean increments or decrements in percentages caused by auditory stimulation before and after conditioning, with changes due to conditioning

\begin{tabular}{|c|c|c|c|c|c|c|c|c|}
\hline \multirow{2}{*}{ Brain area } & \multirow{2}{*}{$\begin{array}{c}N \\
\text { (units) }\end{array}$} & \multicolumn{3}{|c|}{$\begin{array}{l}\text { Early response } \\
\text { (first } 300 \mathrm{msec} \text { ) }\end{array}$} & \multicolumn{3}{|c|}{$\begin{array}{l}\text { Late response } \\
\text { (last } 500 \mathrm{msec} \text { ) }\end{array}$} & \multirow{2}{*}{$\begin{array}{c}\text { Number } \\
\text { of rats }\end{array}$} \\
\hline & & $\begin{array}{l}\text { Before } \\
\text { cond. }\end{array}$ & $\begin{array}{l}\text { After } \\
\text { cond. }\end{array}$ & Change & $\begin{array}{l}\text { Before } \\
\text { cond. }\end{array}$ & $\begin{array}{l}\text { After } \\
\text { cond. }\end{array}$ & Change & \\
\hline Dorsal reticular & 7 & $51 \pm 44$ & $21 \pm 19$ & $-30^{\mathrm{h}} \pm 43$ & $10 \pm 6$ & $16 \pm 20$ & $6 \pm 20$ & 5 \\
\hline Ventral reticular & 10 & $20 \pm 15$ & $26 \pm 13$ & $6 \pm 14$ & $4 \pm$ & $7 \pm 7$ & $3^{h} \pm 3$ & 8 \\
\hline Thalamus & 8 & $21 \pm 11$ & $32^{a} \pm 14$ & $11 \pm 9$ & $6 \pm$ & $18 \pm 16$ & $13 \pm 16$ & 6 \\
\hline Hypothalamus & 10 & $13 \pm 14$ & $22 \pm 31$ & $9 \pm 36$ & $4 \pm 9$ & $11 \pm 26$ & $8 \pm 32$ & 6 \\
\hline Preoptic & 17 & $7 \pm 27$ & $10 \pm 22$ & $3 \pm 27$ & $1 \pm 12$ & $5 \pm 19$ & $4^{\mathrm{h}} \pm 23$ & 13 \\
\hline Hippocampus & 19 & $8 \pm 21$ & $20 \pm 25$ & $13 \pm 30$ & $-9 \pm 13$ & $12^{b} \pm 24$ & $20 \pm 25$ & 8 \\
\hline
\end{tabular}

a Significantly different from pre-conditioning score, 0.05 level, Wilcoxon paired Matched Test.

b Significantly different from pre-conditioning score, 0.01 level, Wilcoxon paired Matched Test.

h Significantly different from hippocampal group, 0.05 level, Mann-Whitney U Test (Siegel 1956).

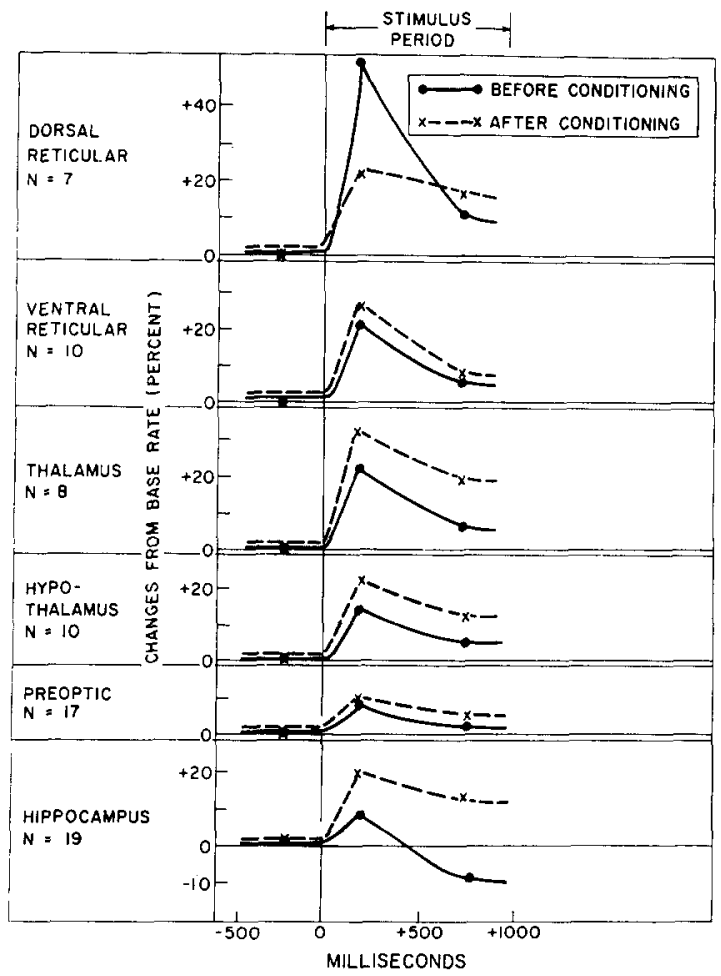

Fig. 2

Averaged incremental or decremental responses before and after conditioning. For each brain area, the rate from baseline for the first 300 and the last $500 \mathrm{msec}$ was computed as a percentage of the baseline rate for the $500 \mathrm{msec}$ prior to stimulation. The average of these scores for the last 50 trials of pseudo-conditioning (before conditioning) and the last 50 trials of conditioning (after conditioning) were used. These scores were averaged for all units in each brain area. increments averaging $13 \%$ appeared in hippocampus; these were reliably different from those of dorsal reticular formation on this score. In second place was an $11 \%$ increment in the thalamic group.

All areas exhibited an average increment in the late response (see Fig. 2); however, this increment was small in reticular formation, hypothalamus, and preoptic area where it ranged from 3 to $8 \%$. It was larger in thalamus and hippocampus, amouting to 13 and $20 \%$ respectively. The hippocampal change in the late response was highly significant by statistical tests and it was significantly larger than the changes in ventral reticular formation and the preoptic group.

Histological material showed that the hippocampal units were all derived from the ridge of hippocampal pyramids, usually near the boundary of the CA-1 and the CA-3 fields; the dorsal reticular units were about $1 \mathrm{~mm}$ lateral to the central grey at its widest point and almost on the boundary line between diencephalon and mesencephalon (see Fig. 3).

\section{DISCUSSION}

During conditioning, unit responses consisting of an increase in firing rate were increased in all areas but one, and decremental responses were attenuated or reversed. This was true for early components in all areas but the dorsal reticular formation, and for late components in all parts of the brain tested. Neuronal firing

Electroenceph. clin. Neurophysiol., 1969, 26: 159-166 


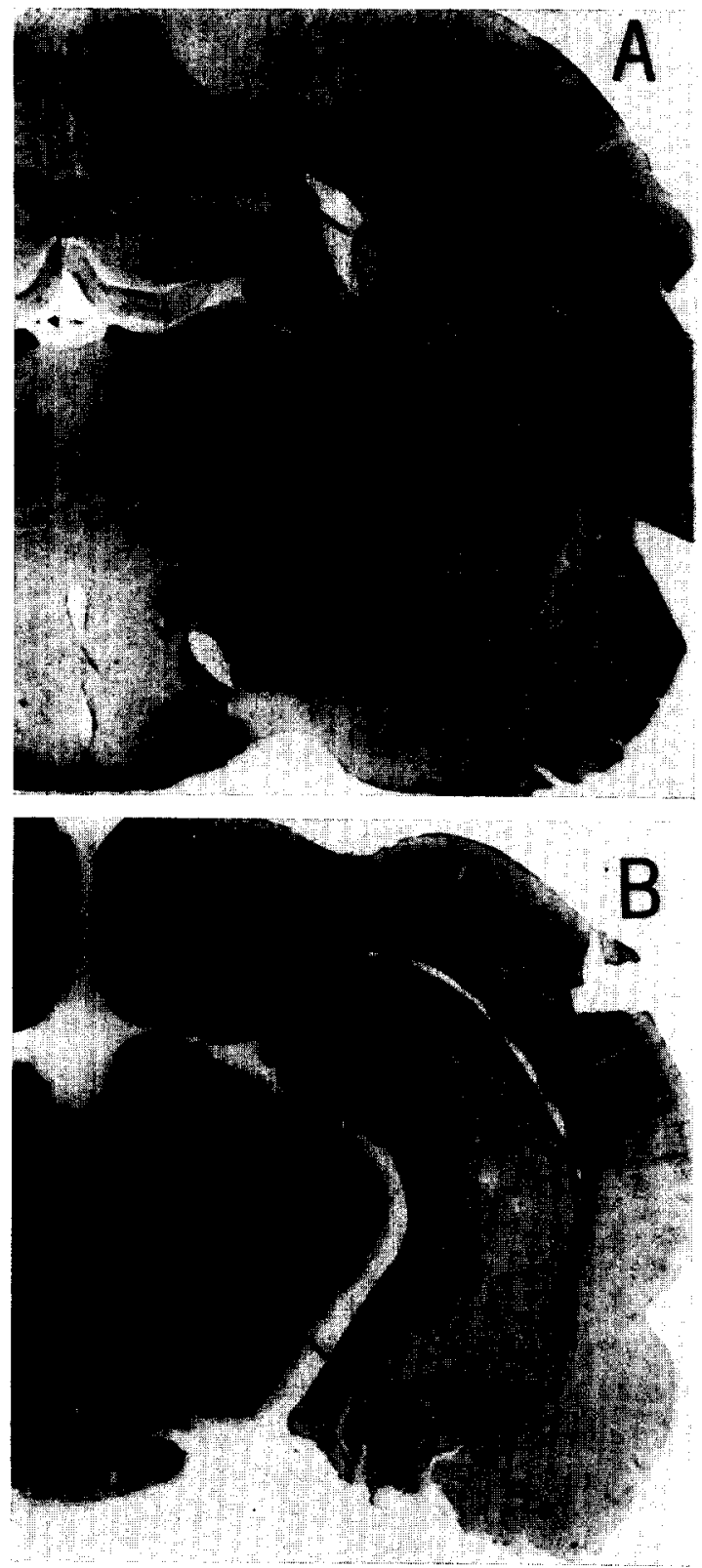

Fig. 3

Histological preparations showing location of probes ( $A$ : hippocampal, $B:$ reticular) whose data are shown in Fig. 2.

rates in hippocampus and thalamus presented, however, the greatest change; those in reticular formation were least affected. As to changes during the course of the $1 \mathrm{sec}$ waiting period, that is during the CS-US interval, there was no special tendency for neurons to become more active toward the point in time where the US would be presented. On the contrary, there was even at the end of conditioning a slight residuum of the initial trend in the opposite direction, that is for neurons to be more active at the onset of the CS than during its last half second. The changes induced by conditioning were, however, most marked in the late period. Many below baseline firing rates which characterized this period after habituation and pseudo-conditioning disappeared and often the early excitatory response lasted into the late period.

Because neuron responses were changed toward an increase in firing rate, suggestive of an excitatory trend, whereas the behavior called for was inhibitory, it would appear that the neuronal activity was not correlated with the amount of overt behavior or with newly learned skeletal movements. Because the stimulus was presented on a random time schedule, catching the animal unaware, it is unlikely that the neuronal activity changes were correlated with orientation responses or postures related to the conditioning. The question arises whether these changes might have been correlated with a tonic muscular state which mediated the behavioral inhibition; this is unlikely as the adoption of a tensed pose, when it was observed after the onset of a trial, regularly tripped the movement detector and caused cancellation of the trial and the data. Because data were taken only for 2 sec periods during which no movement was exhibited, it might be supposed that the data were taken mainly during sleep periods. That the animals were not likely asleep during the conditioning trials was attested by the vigorous capture-response which occurred when the food magazine discharged. In any event, the changes observed were largely in the direction of increased responsiveness to peripheral stimulation, and changes from waking to sleep are regularly in the opposite direction (Evarts 1960). Thus there seems to be little evidence to suggest that any of the new responses observed are correlates of movements, postures, inhibitory processes, or states of sleep. One could, therefore, conclude tentatively that these changes in neuronal firing are correlates of some internal vegetative or preparatory responses related to food, or are correlates of learned motivational or mnemonic traces evoked by the CS. Because the 
hippocampal responses were suggestively similar to some of those observed during food waiting in a previous experiment (Olds et al. 1969), it seems that they might be interpreted in analogy to those data. From these, two characteristics of the hippocampal neuronal activity are relevant: (a) in view of the often large differences between food-waiting and water-waiting response the neurons appeared to be involved in specific anticipatory representations rather than in general activation, inhibition, or arousal; (b) a neuron might participate in an anticipatory response specifically related to food one day and to one specifically related to water several days later. This suggests that if these neuronal activity states are specific representations, they might also be temporary representations. It seems possible, that is, that the neurons involved, instead of bearing some innate relation to food preparatory responses, might be implicated as relatively neutral temporary memory registers which could hold different stimulus-response-reward configurations on different days.

In the quoted set of experiments, interesting accelerating response patterns were observed in the reticular formation, characterized by a crescendo during the last second prior to US
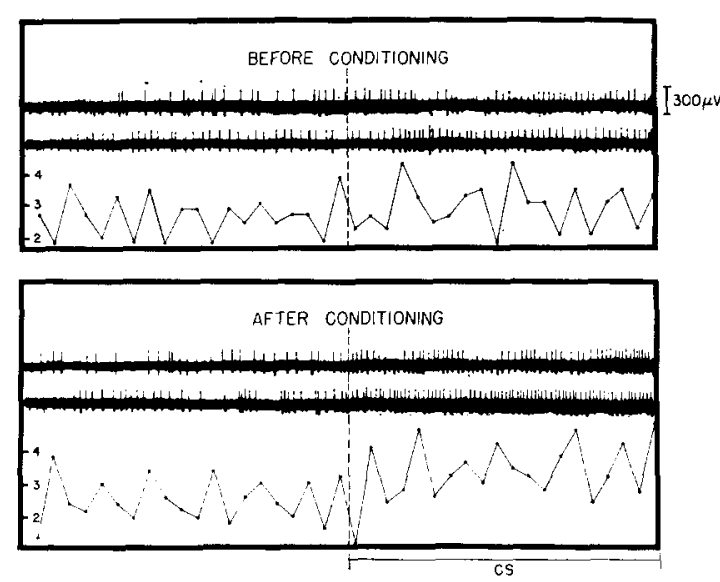

Fig. 4

Dorsal reticular unit activity before and after conditioning. Changes are exemplified by two sample traces (above) and by the average rates for successive $50 \mathrm{msec}$ intervals for each group of 50 trials (below). In' the averaged response curve, each point stands for the averaged response rate for a given $50 \mathrm{msec}$ interval stated in arbitrary units; i.e., the digits along the $\mathrm{Y}$ axis are some multiple or submultiple of the observed average rates. application. The largest accelerating response in reticular formation in the present study was very small (see Fig. 4) and one should therefore conclude that such accelerations were more related to the active pedal behavior or the absence of an explicit CS, which differentiated the two experimental studies, than to the "expectancies" which were common to the two experiments.

If temporary representations are "localized" in hippocampus, what relation might these bear to the organization of behavior? One possibility is that mnemonic traces of a relatively emotional, automatic and temporary character dwell in hippocampal regions whereas another and newer memory system occupies some part of the neocortex. Emotional, automatic and temporary memories might be supposed to characterize the whole memory store among more primitive animals; and in higher species, they might have an important role in constructing and in gating the more unemotional, disengaged and lasting traces.

\section{SUMMARY}

Changes in the firing rates of neurons in various subcortical structures induced by application of a $1 \mathrm{sec}$ auditory stimulus were recorded in unrestrained animals during movement-free intervals. Pseudo-conditioning trials (500) were followed by conditioning trials (300). During the latter, a food pellet was presented to the animal by a dispenser after every stimulus, provided there was no detectable movement during the stimulus period. The difference between the response rates before conditioning and after conditioning was considered to be a measure of the effect induced by the conditioning procedure.

1. Except for the early response in the dorsal reticular formation, responses consisting of incremental firing rate were increased in size and number and decremental responses were attenuated or reversed. Even in the dorsal reticular formation the neuronal activity rate during the last half of the stimulus was augmented.

2. Before conditioning an increment in the firing rate of neurons appeared in most areas during the first $300 \mathrm{msec}$ of stimulation after which the firing rate returned almost to control levels or even systematically below control levels in some areas. In most cases, conditioning procedures caused the early increment to be augmented 
and the neuronal rate to stay elevated above control levels during the remainder of the $1 \mathrm{sec}$ stimulus (thus reversing the decremental tendency where it had appeared).

3. Incremental changes were largest in hippocampus. These changes were, on the basis of deductive arguments, considered to be independent of skeletal and attentional components of the conditioned response on the one hand, and unrelated to sleep and waking or inhibitory processes on the other. It seemed possible therefore that the changes might be related to a short term or temporary trace of a motivationally significant event.

\section{RÉSUMÉ}

\section{RÉPONSES CONDITIONNÉES DES NEURONES HIPPO- CAMPIQUES ET AUTRES}

Pendant des périodes sans mouvements chez des animaux non maintenus, sont enregistrées au niveau des diverses structures sous-corticales, des modifications du taux de décharge neuronique, induites par un stimulus auditif à $1 \mathrm{sec}$. Des essais pseudo-conditionnels (500) sont suivis d'essais conditionnels (300). Au cours de ces derniers, une tablette de nourriture est présentée à l'animal par un distributeur après chaque stimulus, à la condition qu'il n'y ait aucun mouvement décelable pendant la période de stimulation. La différence entre les taux de réponse avant et après conditionnement est prise comme mesure de l'effet induit par le processus de conditionnement.

1. A part la réponse initiale du niveau de la formation réticulaire dorsale, les réponses consistant en accroissement de la fréquence de décharge augmentent en taille et en nombre, alors que celles qui s'accompagnent d'une diminution de la fréquence sont atténuées ou inversées. Même dans la formation réticulaire dorsale, le taux d'activité neuronique est augmenté pendant la dernière moitié du stimulus.

2. Avant le conditionnement, un accroissement de la fréquence de décharge des neurones s'observe dans la plupart des aires au cours des premières $300 \mathrm{msec}$ de stimulation, après lesquelles le taux de dècharge revient à peu près aux niveaux de contrôle ou même systématiquement au-dessous de ces niveaux dans certaines aires. Dans la plupart des cas, les processus de conditionnement déterminent l'augmentation de l'accroissement initial, et le fait que le taux de décharge neuronique reste au-dessus des niveaux de contrôle pendant le reste du stimulus à $1 \mathrm{sec}$ (inversant ainsi la tendance décroissante là où elle était apparue).

3. Les variations de l'accroissement sont les plus grandes dans l'hippocampe. Ces changements sont, sur la base d'arguments déductifs, considérés comme indépendants des composantes physiques et d'attention de la réponse conditionnée d'une part et d'autre part, sans relation avec les processus de sommeil et de veille, ou d'inhibition. Il semble ainsi possible que ces changements puissent être liés à une trace à court terme ou temporaire d'un événement significatif de motivation.

The authors are grateful for technical assistance to G. Baldrighi, W. E. Wetzel, H. J. Frey and W. J. Allan, and for computer programming to P. J. Best.

\section{REFERENCES}

Buchwald, J. S., Halas, E. S. and Schramm, S. Changes in cortical and subcortical unit activity during behavioral conditioning. Physiol. and Behavior, 1966, I: $11-22$.

Ellison, G. D., Humphrey, C. L. and Feeney, D. Some electro-physiological correlates of two behavioral states. J. comp. physiol. Psychol., (in press).

EVARTs, E. V. Effects of sleep and waking on spontaneous and evoked discharges of single units in visual cortex. Fed. Proc., 1960, 19: 828-837.

IsAaCSON, R. L. and WiCKelgren, W. O. Hippocampal ablation and passive avoidance. Science, 1962, 138: 1104-1106.

Kamikawa, K., McIlwain, J. T. and Adey, W. R. Response patterns of thalamic neurons during classical conditioning. Electroenceph. clin. Neurophysiol., 1964, 17: 485-496.

Kawakami, M., Seto, K., Terasawa, E. and Yoshida, K. Mechanisms in the limbic system controlling reproductive functions of the ovary with special reference to the positive feedback of progestin to the hippocampus. In W. R. ADEY and T. TOKIZANE (Eds.) Structure and function of the limbic system. Progress in brain research, Vol.27. Elsevier, Amsterdam, 1967: 69-102.

Maclean, P. D., Denniston, R. H., Dua, S. and Ploog, D. W. Hippocampal changes with brain stimulation eliciting penile erection. In Physiologie de l'Hippocampe. Colloques Internationaux du Centre National de la Recherche Scientifique, No. 107. CNRS, Par is, 1962: 492-510.

Electroenceph. clin. Neurophysiol., 1969, 26: 159-166 
Milner, B. Psychological defects produced by temporal lobe excision. Res. Pub. Ass. nerv. ment. Dis., 1958, 36: 244-257.

NIKI, H. Effects of hippocampal ablation on learning in the rat. In W. R. Adey and T. Tokizane (Eds.), Structure and function of the limbic system. Progress in brain research, Vol. 27. Elsevier, Amsterdam, 1967: 305-317.

OLDS, J. Operant conditioning of single unit responses. Excerpta med., int. Congr. Series No. 87, 1965: 372-380.

OLDS, J. The limbic system and behavioral reinforcement. In W. R. AdEY and T. ToKIZANE (Eds.), Structure and function of the limbic system. Progress in brain research, Vol. 27. Elsevier, Amsterdam, 1967: 144-167.

OLDS, J., MINK, W. D. and BEST, P. J. Single unit patterns during anticipatory behavior. Electroenceph. clin. Neurophysiol., 1969, 26: 144-158.

Orbach, J., Milner, B. and Rasmussen, T. Learning and retention in monkeys after amygdala-hippocampus resection. Arch. Neurol. (Chic.), 1960, 3: 230-251.

Pickenhain, L. and Klingberg, F. Hippocampal slow wave activity as a correlate of basic behavioral mechanisms in the rat. In W. R. AdEY and T. TOKIZANE (Eds.), Structure and function of the limbic system. Progress in brain research, Vol. 27. Elsevier, Amsterdam, 1967: 218-227.

SIEGEL, S. Nonparametric statistics for the behavioral sciences. McGraw-Hill, New York, 1956, $312 \mathrm{p}$.

Travis, R. P. and Sparks, D. L. Changes in unit activity during stimuli associated with food and shock reinforcement. Physiol. and Behavior, 1967, 2: 171-177.

URSIN, R., URSIN, H. and Olds, J. Self-stimulation of hippocampus in rats. J. comp. physiol. Psychol., 1966, 61: 353-359.

YoshiI, N. and OGURA, N. Studies on the unit discharge of brainstem reticular formation in the cat. Med. $J$. Osaka Univ., 1960, 11: 1-17.

Reference: OldS, J. and Hirano, T. Conditioned responses of hippocampal and other neurons. Electroenceph. clin. Neurophysiol., 1969, 26: 159-166. 